\title{
Aplikasi Berbagai Dosis Pupuk UZAAKH dalam Menurunkan Kelarutan Logam Cr pada Tanah Sawah Tercemar Limbah Tekstil
}

\author{
Indra Permana1), Mahfud Arifin²), dan Rija Sudirja ${ }^{2}$ \\ 1) Alumni Program Studi Magister Ilmu Tanah, Faperta UNPAD \\ 2) Staf Pengajar Fakultas Pertanian Universitas Padjadjaran \\ Jl. Raya Bandung Sumedang Km 21 Jatinangor \\ Korespondensi: indra.permana.unpad@gmail.com
}

\begin{abstract}
Degradation of rice field ecosystem by industrial waste contamination caused harmful impact for farming sustainability and crop production production. This study aimed to investigate the effect of various UZAAKH fertilizer dosage and its effect towards cation exchange capacity (CEC), pH, and $\mathrm{Cr}$ solubility reduction in contaminated rice fields from industrial waste. The experiment was conducted in the greenhouse of Agriculture Faculty Universitas Padjadjaran from April to September 2017. Randomized block design with six single treatments: $A=U Z A A K H 150 \mathrm{~kg} \mathrm{ha}^{-1}, B=U Z A A K H$ $250 \mathrm{~kg} \mathrm{ha}^{-1}, C=U Z A A K H 250 \mathrm{~kg} \mathrm{ha}^{-1}, D=U Z A A K H 300 \mathrm{~kg} \mathrm{ha}^{-1}, E=U Z A A K H 350 \mathrm{~kg} \mathrm{ha}^{-1}$, dan F = Urea $200 \mathrm{~kg} \mathrm{ha}-1$, each treatment was replicated four times. The result showed that the application UZAAKH fertilizer has significant effect on CEC, $\mathrm{pH}$, and Cr solubility on the soil. The dosage of $200 \mathrm{~kg}$ $\mathrm{ha}^{-1}$ UZAAKH fertilizer showed the highest CEC 60 day after application. UZAAKH fertilizer with 350 $\mathrm{kg} \mathrm{ha}^{-1}$ dosage was the best dosage to increase soil $\mathrm{pH}$ and decrease $\mathrm{Cr}$ solubility application compared with other UZAAKH fertilizer dosage with the decrease of 69,05\% from initial concentration.
\end{abstract}

Keywords: UZAAKH fertilizer, contaminated rice fields, heavy metal, $\mathrm{Cr}$

\section{PENDAHULUAN}

Kerusakan ekosistem sawah akibat pencemaran limbah industri telah menimbulkan dampak yang merugikan bagi keberlangsungan usaha tani dan pengembangan produksi pertanian. Menurut Sudirja (1998), lahan sawah yang diairi oleh sumber air tercemar limbah secara terus menerus dapat menimbulkan akumulasi bahan pencemar di dalam tanah, yang selanjutnya dapat berakibat buruk terhadap kualitas tanah, jumlah dan kualitas produksi pertanian. Keberadaan logam berat pada lahan sawah sangat berbahaya apabila telah melebihi ambang batas, sehingga perlu adanya upaya reklamasi yang mampu menurunkan kelarutan logam berat tersebut.

Rancaekek merupakan kecamatan yang telah berkembang menjadi kawasan industri di wilayah Bandung bagian Timur Provinsi Jawa Barat. Menurut Wijatmoko dan Hariadi (2008) hasil analisis fisika dan kimia tanah di areal sawah Rancaekek menunjukkan adanya kontaminasi zat-zat penecemar seperti $\mathrm{Fe}, \mathrm{Al}$, $\mathrm{Cu}, \mathrm{Zn}, \mathrm{Pb}, \mathrm{Co}, \mathrm{Cr}$, dan B. Sudirja dkk (2016a) menyatakan bahwa tanah di Desa Linggar Kecamatan Rancaekek yang menunjukkan kadar logam berat $\mathrm{Cr}$ yakni sebesar 78,06 ppm sehingga sudah termasuk dalam kategori kritis. Menurut Ministry of State for Population and Environment of Indonesia, and Dalhousie University Canada (1992) dalam Erfandi dkk, (2014) batas kritis logam berat $\mathrm{Cr}$ pada tanah adalah 2,5 ppm. Oleh karena itu, maka perlu adanya suatu upaya untuk mengurangi ketersediaan logam berat Cr pada lahan sawah di Rancaekek.

Pupuk UZAAK merupakan modifikasi pupuk nitrogen berbahan dasar Urea-ZeolitArang Aktif dan Kompos plus Hayati yang berperan sebagai pupuk lepas lambat dan penjerap logam berat. Pencampuran zeolit dengan pupuk nitrogen menyebabkan amonium yang dikeluarkan oleh pupuk akan dijerap oleh zeolit dan akan dilepaskan kembali ke dalam larutan tanah ketika 
ketersediaan nitrogen tanah rendah (Sudirja dkk, 2016b). Campuran zeolit dan arang aktif pada pupuk mampu menurunkan kelarutan logam berat pada tanah yang tercemar (Susanawati dkk, 2011). Formulasi campuran terbaik antara Urea-Zeolit-Arang aktifKompos plus Hayati diharapkan dapat membantu meningkatkan kualitas lingkungan dan meningkatkan produktivitas hasil padi pada lahan yang tercemar logam berat.

Penelitian ini bertujuan untuk mengetahui pengaruh berbagai dosis pupuk UZAAKH terhadap kapasitas tukar kation (KTK), $\mathrm{pH}$, dan persen penurunan logam $\mathrm{Cr}$ pada tanah sawah tercemar limbah tekstil.

\section{BAHAN DAN METODE}

\subsection{Waktu dan Tempat Penelitian}

Penelitian dilakukan dari bulan April sampai dengan September 2017. Percobaan dilaksanakan di Rumah Kaca Fakultas Pertanian Universitas Padjadjaran Jatinangor, Kabupaten Sumedang, Provinsi Jawa Barat. Lokasi penelitian berada pada ketinggian 822 meter di atas permukaan laut (dpl).

Analisis pupuk UZAAKH dan tanah dilakukan di Laboratorium Kimia Tanah dan Kesuburan Tanah dan Nutrisi Tanaman Fakultas Pertanian Universitas Padjadjaran. Perbanyakan mikroorganisme dilakukan di Laboratorium Mikrobiologi Tanah Fakultas Pertanian Universitas Padjadjaran.

\subsection{Bahan dan Alat Penelitian}

Bahan-bahan yang digunakan dalam penelitian antara lain: tanah sawah yang berasal dari Desa Linggar Kecamatan Rancaekek, Urea, zeolit, arang aktif tempurung kelapa, kompos kotoran sapi dan konsorsium mikroorganisme (Pseudomonas cepacia dan Bacillus subtilis) serta pupuk SP36 dan pupuk $\mathrm{KCl}$ sebagai pupuk dasar.

Alat-alat yang digunakan dalam penelitian antara lain: alat pembuat pupuk granul, ember, timbangan kapasitas $20 \mathrm{~kg}$, baki plastik, penggaris, kertas label dan peralatan lainnya yang mendukung kegiatan penelitian di rumah kaca serta analisis di laboratorium.

\subsection{Pembuatan Pupuk UZAAK}

Proses pembuatan pupuk UZAAK dengan perbandingan formula $60: 20: 20: 10$ (Urea : Zeolit : Arang aktif : Kompos plus Hayati). Bahan-bahan dasar campuran pupuk dihaluskan kemudian disaring hingga lolos ayakan 100 mesh. Proses selanjutnya yakni pencampuran bahan dengan menggunakan mixer agar bahan tercampur secara homogen. Bahan baku yang telah homogen kemudian disemprot air hingga menjadi adonan dan selanjutnya dimasukan ke dalam alat pencetak pupuk. Tahap terakhir yakni memindahkan pupuk yang sudah tercetak ke dalam pan granulator agar didapat bentuk pupuk granul yang bulat (Gambar 1). Proses pengeringan pupuk cukup dikering anginkan pada suhu ruangan.
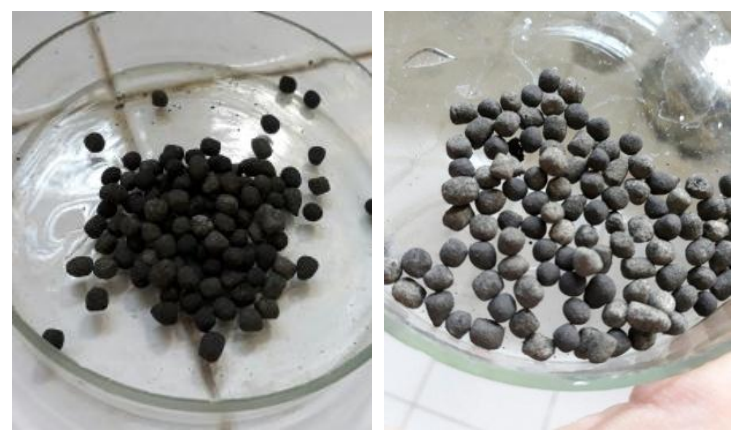

Gambar 1 Pupuk UZAAKH granul

\subsection{Rancangan Percobaan}

Penelitian menggunakan Rancangan Acak Kelompok faktor tunggal yang terdiri dari lima perlakuan dosis pupuk dan satu F (Urea), yaitu ;

$$
\begin{aligned}
& \mathrm{A}=\text { UZAAKH } 150 \mathrm{~kg} \mathrm{ha}^{-1} \\
& \mathrm{~B}=\text { UZAAKH } 200 \mathrm{~kg} \mathrm{ha}^{-1} \\
& \mathrm{C}=\text { UZAAKH } 250 \mathrm{~kg} \mathrm{ha}^{-1} \\
& \mathrm{D}=\text { UZAAKH } 300 \mathrm{~kg} \mathrm{ha}^{-1} \\
& \mathrm{E}=\text { UZAAKH } 350 \mathrm{~kg} \mathrm{ha}^{-1}, \text { dan } \\
& \mathrm{F}=\text { Urea } 250 \mathrm{~kg} \mathrm{ha}^{-1}
\end{aligned}
$$


Masing-masing perlakuan diulang sebanyak empat kali, sehingga terdapat 24 satuan percobaan. Uji beda nyata dilakukan dengan uji F pada taraf $5 \%$. Apabila terdapat pengaruh nyata pada masing-masing perlakuan maka pengujian dilanjutkan dengan uji jarak berganda Duncan.

\section{HASIL DAN PEMBAHASAN}

\subsection{Nilai Kapasitas Tukar Kation (KTK) Tanah}

Hasil analisis statistik menunjukkan bahwa pengaplikasian berbagai dosis pupuk UZAAKH memberikan pengaruh sangat nyata terhadap KTK tanah pada 60 HST (Tabel 1). Pemberian pupuk UZAAKH menunjukkan nilai KTK yang lebih tinggi jika dibandingkan dengan perlakuan $F$ (Urea) pada 60 HST. Perlakuan $\mathrm{F}$ yang hanya diaplikasikan pupuk Urea menunjukkan nilai KTK terendah. Perlakuan B (UZAAKH $200 \quad \mathrm{~kg} \quad \mathrm{ha}^{-1}$ ) menunjukkan nilai $\mathrm{pH}$ tertinggi jika dibandingkan dengan perlakuan lainnya.

Tabel 1 Pengaruh perlakuan pupuk UZAAKH terhadap KTK tanah pada 60 HST

\begin{tabular}{cc}
\hline Perlakuan & KTK $\left(\mathrm{Cmol} . \mathrm{Kg}^{-1}\right)$ \\
\hline A = UZAAK $150 \mathrm{~kg} \mathrm{ha}^{-1}$ & $44,47 \mathrm{c}$ \\
B = UZAAK $200 \mathrm{~kg} \mathrm{ha}^{-1}$ & $47,65 \mathrm{~d}$ \\
C = UZAAK $250 \mathrm{~kg} \mathrm{ha}^{-1}$ & $43,65 \mathrm{bc}$ \\
D = UZAAK $300 \mathrm{~kg} \mathrm{ha}^{-1}$ & $43,00 \mathrm{~b}$ \\
E = UZAAK $350 \mathrm{~kg} \mathrm{ha}^{-1}$ & $44,03 \mathrm{bc}$ \\
F = Urea $250 \mathrm{~kg} \mathrm{ha}^{-1}$ & $41,45 \mathrm{a}$
\end{tabular}

Keterangan: Angka yang diikuti oleh huruf yang sama secara vertikal tidak berbeda nyata menurut Uji Jarak Berganda Duncan pada taraf nyata $5 \%$.

Peningkatan KTK pada perlakuan yang diberikan pupuk UZAAKH disebabkan adanya campuran zeolit, arang aktif, dan kompos sebagai bahan baku pupuk. Zeolit merupakan kelompok mineral alumino-silikat yang mempunyai struktur yang khas dan memiliki nilai KTK yang tinggi (antara 120-180 cmol.kg-1) yang berguna sebagai pengadsorbsi, pengikat dan penukar kation (Suwardi, 2002).

Arang aktif pun merupakan salah satu amelioran yang memiliki KTK sangat tinggi sehingga mampu mengikat kation-kation penting di dalam tanah (Wahyuni dkk., 2016). Aplikasi pupuk UZAAKH memberikan pengaruh positif terhadap kualitas tanah dengan meningkatkan kapasitas tukar kation pada tanah.

\subsection{Nilai pH Tanah}

Berdasarkan hasil analisis uji statistik terdapat perbedaan yang signifikan antara perlakuan pemberian pupuk UZAAKH dengan $\mathrm{F}$ yang hanya Urea saja terhadap nilai $\mathrm{pH}$ tanah pada 60 HST. Hasil analisis nilai pH tanah pada 60 HST disajikan pada Tabel 2.

Tabel 2 Pengaruh dosis pupuk UZAAK terhadap $\mathrm{pH}$ tanah

\begin{tabular}{cc}
\hline Perlakuan & pH tanah \\
\hline A $=$ UZAAK $150 \mathrm{~kg} \mathrm{ha}^{-1}$ & $7,0 \mathrm{~b}$ \\
B = UZAAK $200 \mathrm{~kg} \mathrm{ha}^{-1}$ & $6,8 \mathrm{~b}$ \\
C = UZAAK 250 kg ha-1 & $6,8 \mathrm{~b}$ \\
D = UZAAK $300 \mathrm{~kg} \mathrm{ha}^{-1}$ & $7,0 \mathrm{~b}$ \\
E = UZAAK $350 \mathrm{~kg} \mathrm{ha}^{-1}$ & $6,8 \mathrm{~b}$ \\
F = Urea 250 kg ha-1 & $6,3 \mathrm{a}$
\end{tabular}

Keterangan: Angka yang diikuti oleh huruf yang sama secara vertikal tidak berbeda nyata menurut Uji Jarak Berganda Duncan pada taraf nyata 5\%.

Berdasarkan hasil uji lanjut Duncan pada taraf $5 \%$ perlakuan berbagai dosis pupuk UZAAKH tidak menunjukkan perbedaan yang signifikan pada masing masing perlakuan terhadap nilai $\mathrm{pH}$ tanah, namun perlakuan $\mathrm{F}$ (Urea $250 \mathrm{~kg} \mathrm{ha}^{-1}$ ) berpengaruh terhadap penurunan nilai $\mathrm{pH}$ tanah yang sebelumnya 6,6 (netral) menjadi 6,3 (agak masam). Menurut Damanik dkk (2014) pemberian pupuk Urea dengan dosis tinggi dapat menurunkan $\mathrm{pH}$ tanah dikarenakan pupuk Urea merupakan pupuk bereaksi masam. 
Perubahan amonium menjadi nitrat pada proses nitrifikasi melepaskan ion $\mathrm{H}^{+}$sehingga dapat menurunkan $\mathrm{pH}$ tanah.

Kandungan zeolit pada campuran pupuk mampu meningkatkan $\mathrm{pH}$ tanah. Hal tersebut dikarenakan zeolit mampu mengikat kationkation basa yang terdapat pada tanah sehingga dapat meningkatkan kejenuhan basa dan nilai pH tanah. Abdillah (2008) menyatakan bahwa pemberian zeolit dengan dosis $750 \mathrm{~kg} \mathrm{ha}^{-1}$ mempu meningkatkan nilai $\mathrm{pH}$ sebesar $3,1 \%$ dibandingkan dengan kontrol (tanpa aplikasi zeolit) pada tanah sawah. Zeolit mengalami proses hidrolisis silikat yang menghasilkan ion $\mathrm{OH}^{-}$dengan reaksi sebagai berikut :

$$
\begin{aligned}
& \mathrm{SiO}_{4}^{4-}+\mathrm{H}_{2} \mathrm{O} \rightarrow \mathrm{HSiO}_{4}^{3-}+\mathrm{OH}^{-} \\
& \mathrm{HSiO}_{4}^{3-}+\mathrm{H}_{2} \mathrm{O} \rightarrow \mathrm{H}_{2} \mathrm{SiO}_{4}+\mathrm{OH}^{-} \\
& \mathrm{H}_{2} \mathrm{SiO}_{4}{ }^{2-}+\mathrm{H}_{2} \mathrm{O} \rightarrow \mathrm{H}_{3} \mathrm{SiO}_{4}+\mathrm{OH}^{-} \\
& \mathrm{H}_{2} \mathrm{SiO}_{4}^{-}+\mathrm{H}_{2} \mathrm{O} \rightarrow \mathrm{H}_{4} \mathrm{SiO}_{4}+\mathrm{OH}^{-}
\end{aligned}
$$

(Andyanta, 2000 dalam Abdillah, 2008)

Aplikasi pupuk UZAAKH memberi pengaruh yang baik bagi tanah dengan peningkatan $\mathrm{pH}$ yang akan berdampak kepada meningkatnya ketersediaan unsur hara dalam tanah. Nilai $\mathrm{pH}$ netral adalah nilai yang baik untuk ketersediaan unsur hara bagi tanaman.

\subsection{Penurunan kadar logam Cr}

Hasil uji statistik annova menunjukkan bahwa setiap perlakuan berpengaruh dalam menurunkan logam $\mathrm{Cr}$ dalam tanah pada hari ke 60 HST. Persentase penurunan logam $\mathrm{Cr}$ dalam tanah dari setiap perlakuan dapat dilihat pada Tabel. 3 .

Perlakuan $\mathrm{F}$ yang menggunakan Urea dengan dosis $250 \quad \mathrm{~kg}^{\mathrm{ha}} \mathrm{h}^{-1}$ merupakan perlakuan terbaik dalam menurunkan kelarutan logam $\mathrm{Cr}$ pada tanah dibandingkan perlakuan pupuk UZAAKH. Penurunan kelarutan logam $\mathrm{Cr}$ pada perlakuan $\mathrm{F}$ (Urea $250 \mathrm{~kg} \mathrm{ha}^{-1}$ ) disebabkan terjadinya khelat antara logam $\mathrm{Cr}^{3+}$ dengan $\mathrm{NO}_{3}{ }^{-}$sehingga $\mathrm{Cr}$ menjadi tidak larut di dalam tanah. Damanik dkk (2014) menyatakan bahwa adanya pengaruh pemupukan Urea sebagai faktor penting ketersediaan $\mathrm{N}-\mathrm{NH}_{4}{ }^{+}$yang kemudian mengalami nitrifikasi menjadi $\mathrm{N}^{-\mathrm{NO}_{3}}$ sehingga meningkatkan ketersediaan $\mathrm{N}-\mathrm{NO}_{3}-$ yang diikuti dengan penurunan $\mathrm{pH}$ pada minggu kedua hingga minggu keenam setelah aplikasi.

\begin{tabular}{|c|c|}
\hline Perlakuan & $\begin{array}{c}\text { Penurunan } \\
\text { Logam Cr (\%) }\end{array}$ \\
\hline $\mathrm{A}=\mathrm{UZAAK} 150 \mathrm{~kg} \mathrm{ha}^{-1}$ & $66.56 \mathrm{~b}$ \\
\hline $\mathrm{B}=$ UZAAK $200 \mathrm{~kg} \mathrm{ha}^{-1}$ & $62.31 \mathrm{a}$ \\
\hline $\mathrm{C}=$ UZAAK $250 \mathrm{~kg} \mathrm{ha}^{-1}$ & $68.47 \mathrm{~b}$ \\
\hline $\mathrm{D}=$ UZAAK $300 \mathrm{~kg} \mathrm{ha}^{-1}$ & $68.21 \mathrm{~b}$ \\
\hline $\mathrm{E}=\mathrm{UZAAK} 350 \mathrm{~kg} \mathrm{ha}^{-1}$ & $69.05 \mathrm{~b}$ \\
\hline $\mathrm{F}=$ Urea $250 \mathrm{~kg} \mathrm{ha}^{-1}$ & $77.04 \mathrm{c}$ \\
\hline $\begin{aligned} \text { rangan: Angka yang dii } \\
\text { sama secara ve } \\
\text { nyata menurut } \\
\text { Duncan pada tara }\end{aligned}$ & $\begin{array}{l}\text { oleh huruf yang } \\
\text { a tidak berbeda } \\
\text { Jarak Berganda } \\
\text { ata 5\%. }\end{array}$ \\
\hline
\end{tabular}

Tabel 3 Pengaruh dosis pupuk UZAAK terhadap persentase penurunan kadar logam $\mathrm{Cr}$

Aplikasi pupuk UZAAKH mampu menurunkan kelarutan logam berat secara signifikan. Perlakuan E (UZAAK $350 \mathrm{~kg} \mathrm{ha}^{-1)}$ menunjukan persen penurunan $\mathrm{Cr}$ terlarut yang cukup baik hanya saja tidak berbeda nyata pada hasil uji statistik dengan perlakuan A (UZAAK $150 \mathrm{~kg} \mathrm{ha}^{-1}$ ), D (UZAAK $250 \mathrm{~kg}$ ha1), dan C (UZAAK $250 \mathrm{~kg} \mathrm{ha}^{-1}$ ).

Sudirja dkk (2016a) menyatakan bahwa pupuk UZAAKH tablet dengan formula 60:20:10:10 (Urea :zeolit : arang aktif : kompos) merupakan formula terbaik dalam menurunkan kelarutan logam $\mathrm{Cd}$ dan $\mathrm{Cr}$ di dalam tanah. Penurunan $\mathrm{Cr}$ terlarut terendah ditunjukkan pada perlakuan $\mathrm{B}$ dengan dosis pupuk UZAAK sebanyak $200 \mathrm{~kg} \mathrm{ha}^{-1}$. Hal tersebut dapat disebabkan produk pupuk yang kurang homogen pada saat proses mixing campuran bahan dan pencetakan pupuk granul.

Pupuk UZAAKH mampu menurunkan logam berat pada lahan sawah tercemar 
dikarenakan adanya campuran arang aktif dalam pupuk tersebut yang mempunyai kemampuan untuk mengikat dan mempertahankan ion atau gas didalamnya. Penyerapan menggunakan arang aktif merupakan salah satu cara yang efektif untuk menghilangkan logam berat (Rasjiddin, 2006). Hal ini didukung juga oleh Nasution dan Nurjaya (2008) yang melaporkan bahwa dengan menggunakan arang aktif sebanyak 1 t.ha- ${ }^{-1}$ dapat menurunkan kadar logam berat di tanah sebanyak $39 \%$.

Penurunan ketersediaan $\mathrm{Cr}$ dalam tanah disebabkan karena adanya bahan amelioran zeolit yang memiliki kemampuan meningkatkan kapasitas tukar kation (Tabel 1) dan $\mathrm{pH}$ tanah (Tabel 2), sehingga berpengaruh pada kadar $\mathrm{Cr}$ dalam tanah. Menurut Kismolo dkk (2012) zeolit merupakan amelioran yang mempunyai sifat absorben sehingga memiliki daya jerap tinggi terhadap kation-kation logam berat dalam tanah.

Peningkatan $\mathrm{pH}$ mampu menyebabkan penjerapan logam berat menjadi lebih tinggi. Hal tersebut dikarenakan kompetisi $\mathrm{H}^{+}$ dengan ion logam menjadi berkurang saat kondisi $\mathrm{pH}$ tinggi sehingga proses penjerapan ion logam semakin besar jika dibandingkan pada $\mathrm{pH}$ rendah (Alkaninwor, 2007).

Penggunaan kompos sebagai bahan baku pupuk berperan dalam menurunkan kelarutan logam $\mathrm{Cr}$ pada tanah. kompos mengandung bahan organik yang mampu menurunkan kelarutan logam sehingga menjadi tidak tersedia bagi tanaman. Berdasarkan hasil penelitian Adji (2006) pemberian kompos mampu menurunkan kelarutan logam $\mathrm{Pb}, \mathrm{Cd}$, dan $\mathrm{Cr}$ masing-masing hingga $67,66 \%, 37,30 \%$ dan $17,23 \%$ dengan variasi dosis antara 20 sampai dengan 80 gram pot ${ }^{-1}$ atau 5 - 20 ton ha-1.

Bakteri Pseudomonas sp. yang diinokulasikan pada kompos dinilai mampu menyerap logam berat Krom (Cr), Kadnium (Cd), Timbal $(\mathrm{Pb})$, Tembaga $(\mathrm{Cu})$ dan Seng (Zn) (Vijayaraghvan et. al., 2008). Aplikasi pupuk UZAAKH memberikan pengaruh positif terhadap tanah karena mampu menurunkan kelarutan logam $\mathrm{Cr}$ pada tanah tercemar. Gambar 2 menunjukkan presentase penurunan kelarutan logam $\mathrm{Cr}$ pada masingmasing perlakuan yang diukur pada $60 \mathrm{HST}$.

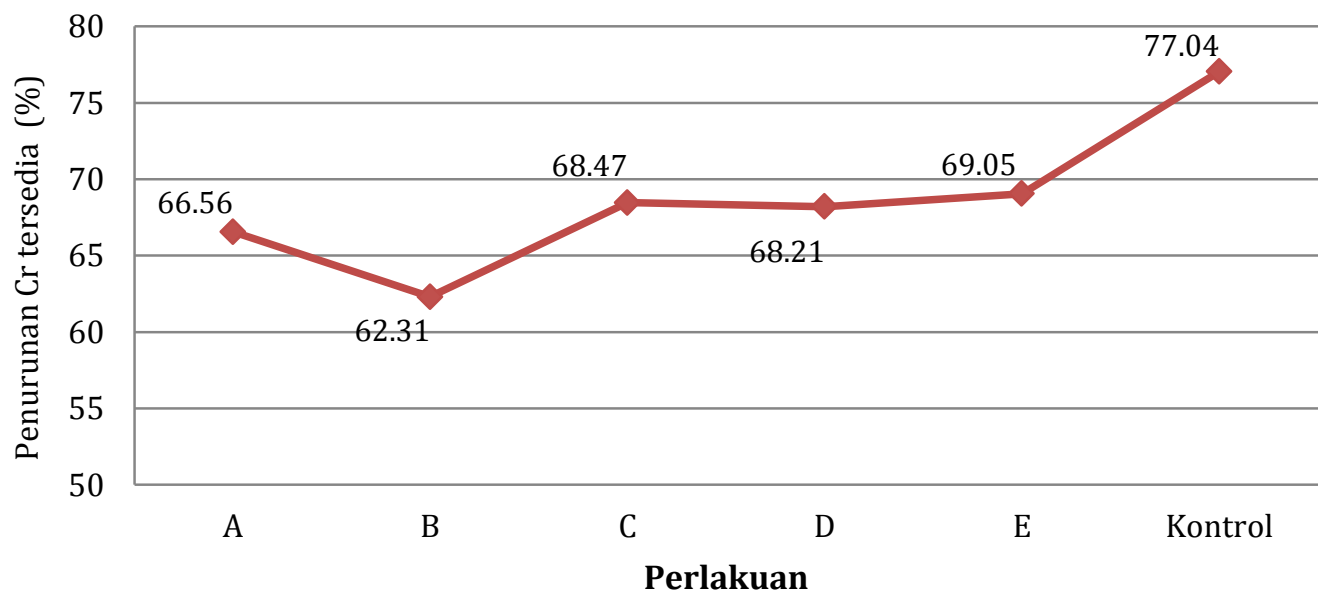

Gambar 2 Persentase penurunan $\mathrm{Cr}$ tersedia pada masing-masing perlakuan

Setiap perlakuan mampu menurunkan kelarutan $\mathrm{Cr}$ diatas $60 \%$ setelah pengaplikasian pupuk. Perlakuan A, C, D, dan E merupakan memiliki kemampuan yang tidak berbeda nyata secara statistik dalam menurunkan kelarutan logam $\mathrm{Cr}$ dalam tanah dengan masing-masing nilai persen penurunan antara lain $66,56 \%, 68,47 \%$, 
68,21\% dan 69,05\%. Perlakuan B (UZAAK $200 \mathrm{~kg} \mathrm{ha}^{-1}$ ) merupakan perlakuan yang memiliki kemampuan menurunkan kelarutan $\mathrm{Cr}$ terendah jika dibandingkan dengan perlakuan dosis pupuk UZAAKH lainnya dengan persen penurunan $62,31 \%$.

Perlakuan $F$ yang diaplikasikan Urea dengan dosis $250 \mathrm{~kg} \mathrm{ha}^{-1}$ mampu menurunkan kelarutan logam $\mathrm{Cr}$ hingga 77,04\%, sangat baik dibandingkan dengan perlakuan lainnya. Hal tersebut dikarenakan Urea yang melepaskan $\mathrm{N}$ dalam bentuk $\mathrm{NH}_{4}{ }^{+}$(amonium) cepat berubah bentuk atau mengalami nitrifikasi menjadi $\mathrm{NO}_{3}{ }^{-}$(nitrat). Keberadaan $\mathrm{NO}_{3}$ - di dalam tanah berpengaruh terhadap kelarutan logam berat sehingga membentuk endapan logam $\left(\mathrm{CrNO}_{3}\right)$.

\section{KESIMPULAN}

Aplikasi pupuk UZAAKH berpengaruh terhadap KTK, nilai $\mathrm{pH}$ dan penurunan kelarutan $\mathrm{Cr}$ pada tanah sawah tercemar limbah tekstil. Dosis pupuk UZAAKH $200 \mathrm{~kg}$ ha $^{-1}$ merupakan perlakuan terbaik dalam meningkatkan nilai KTK tanah pada 60 HST. Pupuk UZAAKH dengan dosis $350 \mathrm{~kg} \mathrm{ha}^{-1}$ merupakan dosis terbaik dalam meningkatkan nilai $\mathrm{pH}$ dan menurunkan kelarutan $\mathrm{Cr}$ tanah pada 60 HST diabndingkan perlakuan pupuk UZAAKH lainnya dengan persen penurunan hingga 69,05 \% dari konsentrasi awal.

\section{UCAPAN TERIMA KASIH}

Ucapan terima kasih ditujukan kepada Program Strategis Nasional (STRANAS) DIKTI atas dana penelitian yang diberikan pada tahun 2016 dan 2017.

\section{DAFTAR PUSTAKA}

Abdillah, A. 2008. Pengaruh Zeolit Dan Pupuk K Terhadap Ketersediaan Dan Serapan K Tanaman Padi Di Lahan Pasir Pantai Kulonprogo. Fakultas
Pertanian Universitas Sebelas Maret, Surakarta. Skripsi.

Damanik, A.R.B., H. Hanum, Sarifudin. 2014. Dinamika $\mathrm{N}-\mathrm{NH}_{4}$ dan $\mathrm{NO}_{3}$ akibat pemberian pupuk urea dan kapur $\mathrm{CaCO}_{3}$ pada tanah Inceptisol Kwala Bekala dan kaitannya terhadap pertumbuhan tanaman jagung. Jurnal Online Agroekoteknologi 2 (3): $1218-1227$.

Susanawati, L.D., B. Suharto dan Kustamar. 2011. Penurunan logam berat pada air lindih dengan media zeolit menggunakan metode batch dan metode kontinyu. Agrointek 5 (2): $126-132$.

Nasution, I., dan Nurjaya. 2008. Pengaruh amelioran zeolit, bahan organik dan karbon aktif terhadap kadar $\mathrm{Cd}$ dalam tanah dan serapannya dalam bawang merah di Inceptisol Tegal. Prosiding Seminar Nasional Pengendalian Pencemaran Lingkungan Pertanian melalui Pendekatan Pengelolaan Daerah Aliran Sungai (DAS) secara Terpadu. Buku 1. Hal: 190-201. Surakarta, 28 Maret 2006. Balai Penelitian Lingkungan Pertanian.

Sudirja, R. 1998. Evaluasi Pengaruh Tanah Terpapar Air Buangan Industri Tekstil terhadap Pertumbuhan dan Hasil Tanaman Padi Sawah (Oryza sativa L.), serta Beberapa Serapan Unsur Logam Berat. Institut Teknologi Bandung, Bandung. Tesis.

Sudirja, R., B. Joy, S. Rosniawaty, A. Setiawan, dan R. I. Yunianto. 2016a. Pengaruh formulasi pupuk urea-zeolitarangaktif terhadap $\mathrm{pH}, \mathrm{N}$-total, KTK tanah dan residu $\mathrm{Pb}$ pada tanah sawah tercemar limbah industri. Jurnal Soilrens, 14 (1): 17 22. 
Sudirja, R. B. Joy, dan S. Rosniawaty. 2016b. Pengaruh beberapa formulasi pupuk UZAH terhadap ketersediaan $\mathrm{N}$ dan kelarutan $\mathrm{Cd}$ dan $\mathrm{Cr}$ di lahan tercemar limbah industri. Jurnal Soilrens 14(2): 104-112.

Suwardi. 2002. Prospek pemanfaatan mineral zeolit di bidang pertanian.. Jurnal Zeoilt Indonesia 1(1): 5 - 12.

Wahyuni, S., Indratin, E. Sulaeman, dan A.N Ardiwinata. 2016. Pelapisan urea dengan arang aktif yang diperkaya mikroba dapat mempercepat penurunan konsentrasi residu insektisida heptaklor di lahan sawah. Informatika Pertanian 25(2): $155-162$.

Wijatmoko, B. dan Hariadi. 2008. Studi pola sebaran dan kedalaman air tanah berdasarkan nilai resistivitas disekitar saluran pembuangan air limbah industri Rancaekek Kabupaten Bandung. Jurnal Bionatura 10 (1): 58 - 67 . 